\title{
Early gastric cancer with multiple submucosal heterotopic gastric gland: A case report
}

\author{
TSUTOMU NAMIKAWA $^{1}$, NOBUKO ISHIDA ${ }^{1}$, KEIICHIRO YOKOTA $^{1}$, ERI MUNEKAGE $^{1}$, \\ JUN IWABU ${ }^{1}$, MASAYA MUNEKAGE ${ }^{1}$, SUNAO UEMURA ${ }^{1}$, HIROMICHI MAEDA ${ }^{2}$, \\ HIROYUKI KITAGAWA $^{1}$, MICHIYA KOBAYASHI ${ }^{2,3}$ and KAZUHIRO HANAZAKI ${ }^{1}$ \\ ${ }^{1}$ Department of Surgery, Kochi Medical School; ${ }^{2}$ Cancer Treatment Center, Kochi Medical School Hospital; \\ ${ }^{3}$ Department of Human Health and Medical Sciences, Kochi Medical School, Nankoku, Kochi 783-8505, Japan
}

Received October 19, 2018; Accepted April 17, 2019

DOI: $10.3892 / \mathrm{mco} .2019 .1846$

\begin{abstract}
A case of early gastric cancer involving multiple submucosal gastric glands that was treated by distal gastrectomy was described in the present case report. An 85-year-old man was referred to our hospital for the treatment of gastric cancer. Esophagogastroduodenoscopy revealed an irregular, nodular, elevated lesion on the posterior wall of the middle third of the stomach, and biopsy specimens indicated well-differentiated tubular adenocarcinoma. Submucosal tumor (SMT)-like lesions were detected in the area adjacent to the nodular lesion, in the anterior wall side of the middle third of the stomach. Abdominal contrast-enhanced computed tomography showed cystic lesions in the middle part of the stomach, and no mass lesions in the liver. The patient underwent distal gastrectomy with regional lymphadenectomy. Macroscopic examination of the resected specimen showed an SMT-like lesion measuring 2.8x2.6 cm in contact with a superficial, depressed lesion measuring $1.7 \times 0.9 \mathrm{~mm}$ in the middle third of the stomach, and another SMT-like lesion measuring $1.5 \times 1.4 \mathrm{~cm}$ in diameter, which was also in the middle third of the stomach. The pathological diagnosis was well-differentiated tubular adenocarcinoma invading the gastric submucosal layer without lymph node metastasis, but with nearby submucosal heterotopic gastric gland (SHGG) detected. Following surgery, the patient remained symptom-free without evidence of recurrence for 3 months. The finding of SHGG remains a rare entity, and further studies are warranted to clarify the association between these submucosal lesions and the development of cancer.
\end{abstract}

Correspondence to: Dr Tsutomu Namikawa, Department of Surgery, Kochi Medical School, Kohasu, Oko-cho, Nankoku, Kochi 783-8505, Japan

E-mail: tsutomun@kochi-u.ac.jp

Key words: submucosal heterotopic gland, gastric cancer, submucosal tumor

\section{Introduction}

Submucosal heterotopic gastric gland (SHGG) is a rare entity characterized by ectopic proliferation of gastric glandular elements in the lamina propria and reported in 3.0-20.1\% of gastric cancer cases worldwide $(1,2)$. Gastric cancer is a common malignant tumor reported to be the seventh leading cause of cancer mortality worldwide, and the second-most frequent cause of cancer-related deaths in Japan $(3,4)$. While SHGG is considered a benign disease, and close follow-up by endoscopy is the recommended treatment strategy, a few cases of gastric carcinogenesis associated with SHGG have been reported $(1,2,5)$. Herein, we report a case of early gastric cancer with multiple SHGGs treated by distal gastrectomy.

\section{Case report}

An 85-year-old Japanese man with a past history of right hemicolectomy for an ascending colon cancer 11 years earlier visited his local doctor for a periodic medical examination. Esophagogastroduodenoscopy (EGD) revealed an early gastric cancer diagnosed as adenocarcinoma on biopsy, and the patient was referred to our hospital. Physical examination on admission was unremarkable and the laboratory findings were as follows: normal red blood cell count $\left(441 \times 10^{4} / \mathrm{mm}^{3}\right.$; normal range, $435-555 \times 10^{4} / \mathrm{mm}^{3}$ ), normal white blood cell count $\left(5.8 \times 10^{3} / \mathrm{mm}^{3}\right.$; Normal range, $\left.3.3-8.6 \times 10^{3} / \mathrm{mm}^{3}\right)$, and elevated C-reactive protein levels $(0.16 \mathrm{mg} / \mathrm{dl}$; normal range, $<0.14 \mathrm{mg} / \mathrm{dl})$. An analysis of serum tumor markers revealed elevated carcinoembryonic antigen levels $(4.5 \mathrm{ng} / \mathrm{ml}$; normal range, $<3.5 \mathrm{ng} / \mathrm{m})$, elevated carbohydrate antigen (CA) $72-4$ levels $(7.3 \mathrm{U} / \mathrm{ml}$; normal range, $<5.3 \mathrm{U} / \mathrm{ml})$, Normal CA 125 levels $(16.9 \mathrm{U} / \mathrm{ml}$; normal range, $<35 \mathrm{U} / \mathrm{ml})$, normal CA 19-9 levels (19.6 U/ml; normal range, $<37 \mathrm{U} / \mathrm{ml})$, and normal alpha-fetoprotein levels $(4.8 \mathrm{ng} / \mathrm{ml}$; normal range, $<100 \mathrm{ng} / \mathrm{ml}$ ). The carbon-13 urea breath test to examine Helicobacter pylori infection was positive.

A second EGD showed an irregular nodular elevated lesion on the greater curvature side of the middle third of the stomach that was diagnosed on biopsy as well-differentiated adenocarcinoma. Submucosal tumor (SMT)-like lesions were also detected in an adjacent area on the anterior wall of the 


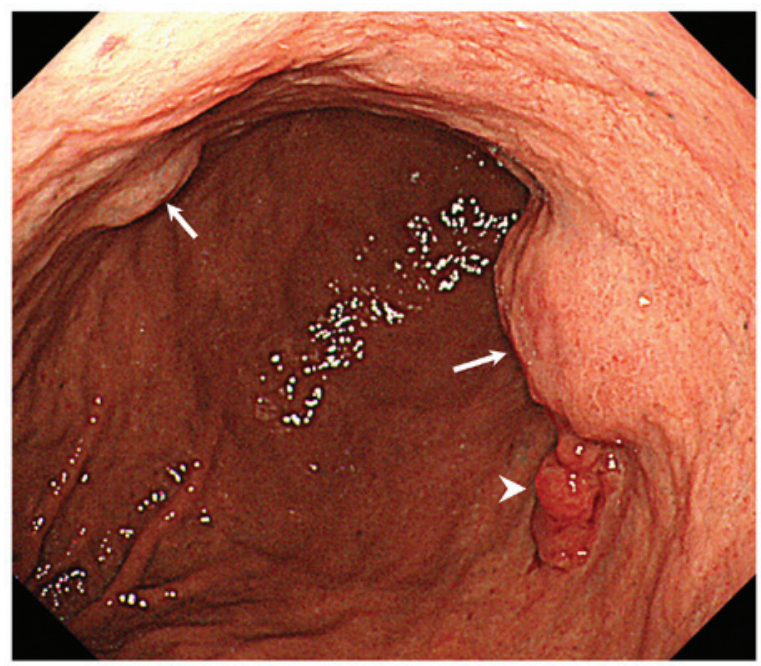

Figure 1. Esophagogastroduodenoscopy showing a nodular elevated lesion (arrow) on the posterior wall of the middle third of the stomach, and submucosal tumor-like lesions on the area adjacent to the nodular lesion on the anterior wall of the middle third of the stomach (arrowhead).

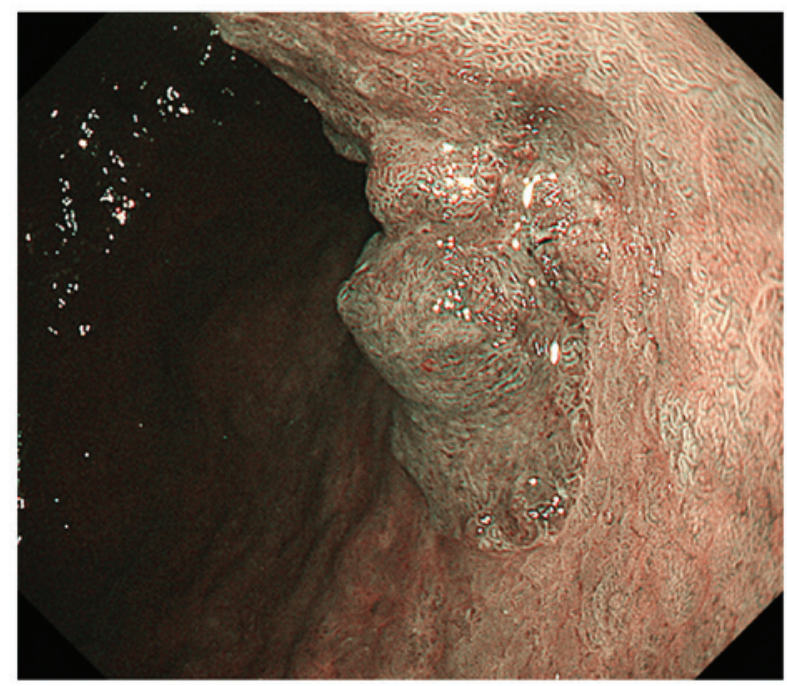

Figure 2. Magnifying endoscopy with narrow-band imaging showing irregular microvascular and microsurface pattern in nodular elevated lesion, and normal pattern in submucosal tumor-like lesion.

middle third of the stomach (Fig. 1). Magnifying endoscopy with narrow-band imaging showed irregular microvascular and microsurface pattern in nodular elevated lesion, and normal pattern in SMT-like lesion (Fig. 2). Abdominal contrast-enhanced computed tomography (CT) showed cystic lesions in the middle part of the stomach, but no enlarged perigastric lymph nodes or mass lesions in the liver (Fig. 3). Under a clinical diagnosis of T1N0M0, stage IA according to the 8th International Union Against Cancer (UICC) TNM classification (6), the patient underwent distal gastrectomy with regional lymphadenectomy followed by Billroth I reconstruction.

Macroscopic examination of the resected specimen showed an SMT-like lesion measuring $2.8 \times 2.6 \mathrm{~cm}$ in contact with a superficial depressed lesion measuring $1.7 \times 0.9 \mathrm{~cm}$ in the posterior wall of the middle third of the stomach, and

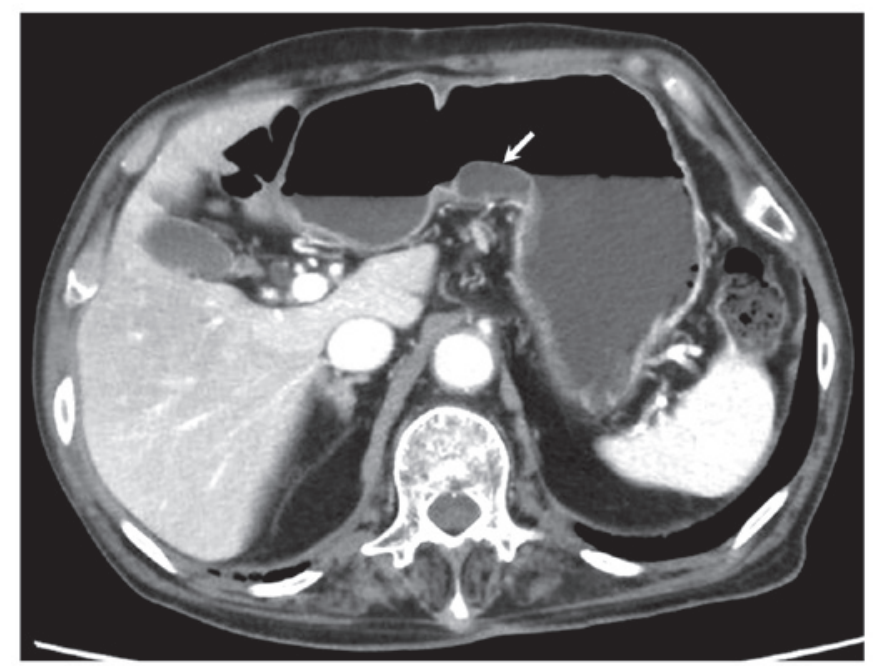

Figure 3. Abdominal contrast-enhanced computed tomography showing cystic lesions in the middle part of the stomach measuring $2.8 \mathrm{~cm}$ in diameter (arrow).

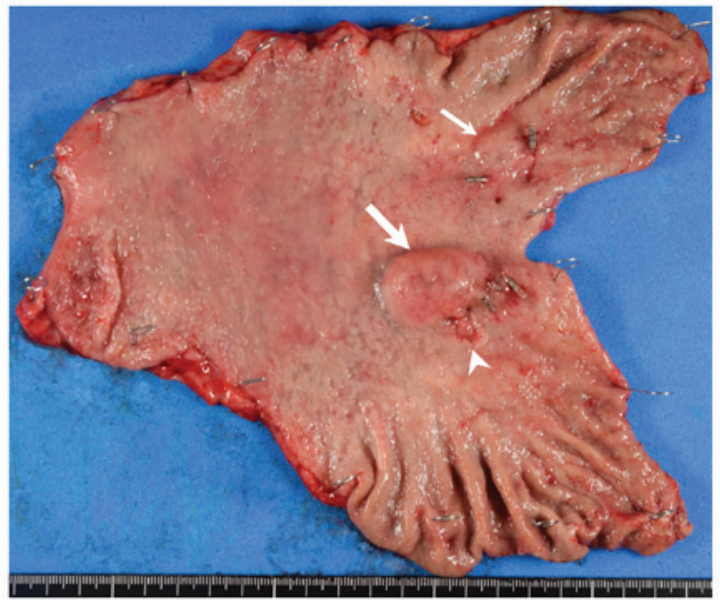

Figure 4. Gross appearance of the surgically resected specimen showing a submucosal tumor (SMT)-like lesion measuring 2.8x2.6 cm (large arrow) in contact with a superficial depressed lesion measuring $1.7 \times 0.9 \mathrm{~mm}$ in the middle third of the stomach (arrowhead), and another SMT-like lesion measuring $1.5 \times 1.4 \mathrm{~cm}$ in diameter, which was also in the middle third of the stomach (small arrow).

another SMT-like lesion measuring $1.5 \times 1.4 \mathrm{~cm}$ in the anterior wall of the middle third of the stomach (Fig. 4). The superficial depressed lesion was diagnosed pathologically as well-differentiated tubular adenocarcinoma invading the gastric submucosal layer (Fig. 5). The SMT-like lesions consisted of glandular structures, showing irregular branching and cystic formation with no dysplasia, and were diagnosed as SHGG (Fig. 5). There were no signs of malignancy in the SHGG, and neither lymphovascular invasion nor lymph node metastasis was evident.

Following an uneventful postoperative course, the patient was discharged on postoperative day 10 and has been well with no evidence of recurrence for 3 months following the operation. Written informed consent was obtained from the patient for publication of this Case Report and any accompanying images. 


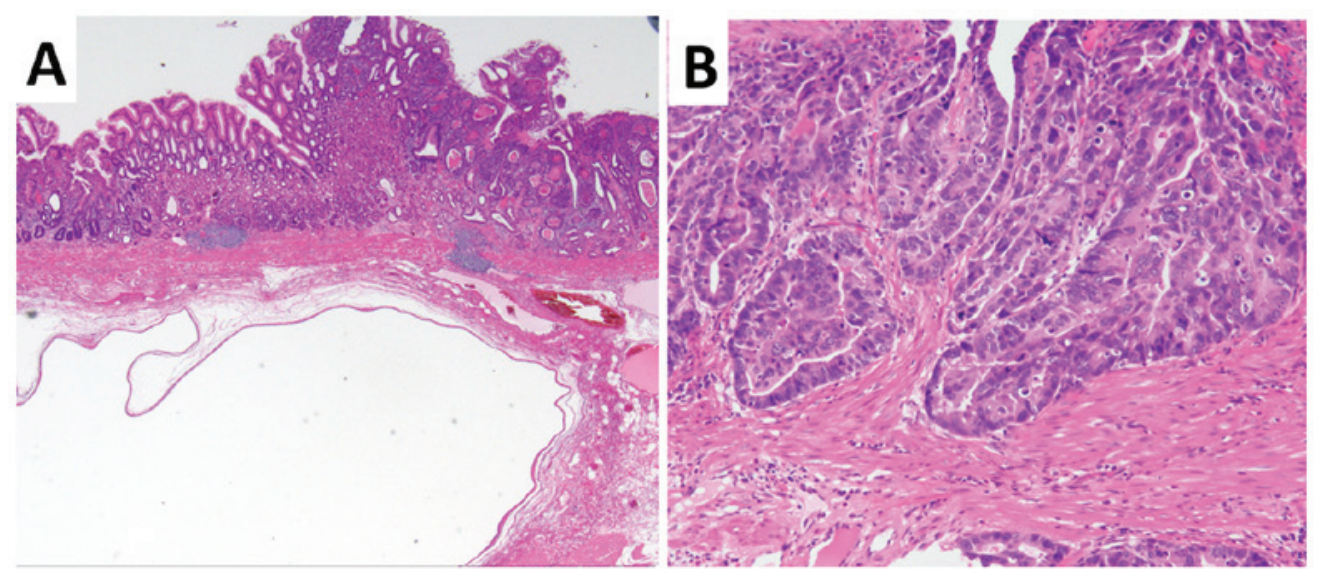

Figure 5. Histological findings of the resected specimen demonstrated a well-differentiated adenocarcinoma invading the submucosal layer [(A) magnification, x40; (B) magnification, x200], with a large cystic formation in the submucosa.

\section{Discussion}

We presented a rare case of SHGG in a patient with gastric cancer who underwent distal gastrectomy. SHGG is a relatively rare entity that is considered benign and is rarely associated with malignant transformation (7). To the best of our knowledge, this is the first reported case of multiple SHGG presenting as SMT-like lesions accompanying gastric cancer.

SHGG is thought to arise from gastric glands existing congenitally in the submucosa, or from aberration of the epithelium into the submucosa as a result of repeated erosion and regeneration of the mucosa $(1,8)$. The present case showed no obvious pathological continuity between the SHGG and gastric cancer, despite the two lesion types being in close proximity, and indeed, little is known about the possibly carcinogenesis of SHGG $(1,2,5,9)$. The dominant purported mechanism regarding an association between SHGG and gastric cancer is that both entities develop in coincidence with repeated erosion and regeneration of the mucosa, and that SHGG are paracancerous lesions $(8,9)$. In support of this, the histological characteristics of SHGG with cystic expansion are similar to gastritis cystic profunda (GCP), which can occur at anastomotic sites after gastrectomy (10). GCP is an uncommon, hyperplastic, benign lesion characterized by cystic dilatation of the gastric glands extending into the submucosa of the stomach that follows mucosal injury caused by a surgical procedure or suturing technique promoting mucosal prolapse and herniation of glands into the submucosa $(10,11)$. GCP therefore usually occurs at a gastroenterostomy site, although it can also be found in undisturbed stomach, and it is considered a potentially precancerous lesion (10).

As other similar potentially precancerous lesion, Barrett's esophagus is thought to be a premalignant condition, which has strong association with esophageal adenocarcinoma. Abbasi et al reported that Barrett's epithelial metaplasia that completely eliminated after several years of treatment with proton pump inhibitor (12). A reduction of cancer risk might be anticipated if treatment could induce a regression of Barrett's epithelial metaplasia.

SHGG can present as elevated lesions covered with normal mucosa such as SMT in EGD (13). In the case of gastric cancer originated from SHGG is difficult to diagnose, because cancer exists at the submucosa, and cancer components are not exposed on the surface (14). Endoscopic ultrasonography (EUS) is considered a useful modality for both detecting SHGG and judging the depth of lesion invasion, because it can reveal hypoechoic scattered cystic lesions within a heterogeneous area $(13,15)$. In the present case, the pathologic evaluation led to a diagnosis of SHGG after surgery. Based on the EUS findings, fine needle biopsy might be useful to diagnose this entity preoperatively.

There are no previous reports of gastric cancer with multiple SHGG presented as SMT-like lesions in the English literature; however, Tsuji et al (16) reported multiple early gastric tumors of varied histological types associated with GCP, and speculated that repeated erosion and regeneration induced by chronic inflammation causes multicentric carcinogenesis as well as an aberration of the gastric glands. Accordingly, multiple SHGG as well as GCP might be risk factors for gastric cancer.

In conclusion, the association of gastric cancer and SHGG remains controversial with respect to both carcinogenesis and patient treatment strategies. Nevertheless, it is important to take SHGG into consideration for the differential diagnosis of SMT of the stomach, and further assessments by accumulation of additional cases are needed to understand the various presentations of this rare entity.

\section{Acknowledgements}

Not applicable.

\section{Funding}

No funding was received.

\section{Availability of data and materials}

Not applicable.

\section{Authors' contributions}

TN contributed to the writing of the manuscript. MK and $\mathrm{KH}$ supervised the study. NI, KY, EM, JI, MM, SU, HM and HK 
served as the attending physicians for the presented patient. All the authors have read and approved that final version of this manuscript.

\section{Ethics approval and consent to participate}

Not applicable.

\section{Patient consent for publication}

The patient has given consent for the publication of the case details and associated images.

\section{Competing interests}

The authors declare that they have no competing interests to disclose.

\section{References}

1. Hagiwara T, Kakushima N, Imai K, Tanaka M, Takao T, Hotta K Yamaguchi Y, Takizawa K, Matsubayashi H, Ono H, et al: Early gastric cancer with spreading to heterotopic gastric glands in the submucosa: A case report and review of the literature. Clin J Gastroenterol 7: 123-128, 2014.

2. Kosugi S, Kanda T and Hatakeyama K: Adenocarcinoma arising from heterotopic gastric mucosa in the stomach. J Gastroenterol Hepatol 21: 483-484, 2006.

3. Nashimoto A, Akazawa K, Isobe Y, Miyashiro I, Katai H, Kodera Y, Tsujitani S, Seto Y, Furukawa H, Oda I, et al: Gastric cancer treated in 2002 in Japan: 2009 annual report of the JGCA nationwide registry. Gastric Cancer 16: 1-27, 2013.

4. Fidler MM,Gupta S, SoerjomataramI,Ferlay J,Steliarova-FoucherE and Bray F: Cancer incidence and mortality among young adults aged 20-39 years worldwide in 2012: A population-based study. Lancet Oncol 18: 1579-1589, 2017.

5. Imamura T, Komatsu S, Ichikawa D, Kobayashi H, Miyamae M, Hirajima S, Kawaguchi T, Kubota T, Kosuga T, Okamoto K, et al: Gastric carcinoma originating from the heterotopic submucosal gastric gland treated by laparoscopy and endoscopy cooperative surgery. World J Gastrointest Oncol 7: 118-122, 2015.
6. Brierley JD, Gospodarowicz MK and Wittekind C (eds). TNM classification of malignant tumours (8th Edition). New York: John Wiley \& Sons, 2017.

7. Rubio CA and Mandai K: Gastric adenocarcinomas in displaced mucosal glands. Anticancer Res 19: 2381-2385, 1999.

8. Iwanaga T, Koyama H, Takahashi Y, Taniguchi H and Wada A: Diffuse submucosal cysts and carcinoma of the stomach. Cancer 36: 606-614, 1975.

9. Manabe S, Mukaisho KI, Yasuoka T, Usui F, Matsuyama T, Hirata I, Boku Y and Takahashi S: Gastric adenocarcinoma of fundic gland type spreading to heterotopic gastric glands. World J Gastroenterol 23: 7047-7053, 2017.

10. Namikawa T, Kawanishi Y, Fujisawa K, Munekage E, Munekage M, Maeda H, Kitagawa H, Kobayashi M and Hanazaki K: Gastric adenocarcinoma at the anastomotic site 50 years after gastrojejunostomy: A case report. Mol Clin Oncol 7: 249-251, 2017.

11. Lee TH, Lee JS and Jin SY: Gastritis cystica profunda with a long stalk. Gastrointest Endosc 77: 821-822; discussion 822, 2013.

12. Abbasi BA, Rubaye AA and Ahmed N: Complete disappearance of Barrett's epithelial metaplasia following long term proton pump inhibitor therapy. J Med Discov 2: jmd17016, 2017.

13. Hizawa K, Matsumoto T, Kouzuki T, Suekane H, Esaki M and Fujishima M: Cystic submucosal tumors in the gastrointestinal tract: Endosonographic findings and endoscopic removal. Endoscopy 32: 712-714, 2000.

14. Itoh K, Tsuchigame T, Matsukawa T, Takahashi M, Honma K and Ishimaru Y: Unusual gastric polyp showing submucosal proliferation of glands: Case report and literature review. J Gastroenterol 33: 720-723, 1998.

15. Hashimoto R, Hamamoto H, Omori Y and Tanuma T: Early gastric cancer on submucosal heterotopic gastric glands. Gastrointest Endose 85: 851-852, 2017.

16. Tsuji T, Iwahashi M, Nakamori M, Ueda K, Ishida K, Naka T, Ojima T, Akamatsu $\mathrm{H}$ and Yamaue $\mathrm{H}$ : Multiple early gastric cancer with gastritis cystica profunda showing various histological types. Hepatogastroenterology 55: 1150-1152, 2008.

(i) $(-)$ This work is licensed under a Creative Commons Attribution-NonCommercial-NoDerivatives 4.0 International (CC BY-NC-ND 4.0) License. 